\title{
Recepción del cine soviético en España: una historia entre guerras, censuras y aperturas
}

\author{
Jorge Latorre Izquierdo \\ Antonio Martínez Illán \\ Rafael Llano Sánchez ${ }^{* * *}$
}

Recibido: 27 de agosto de 2010 Aprobado: 30 de septiembre de 2010

\begin{abstract}
Resumen
Este artículo reconstruye la historia de la exhibición del cine soviético en España desde la década de los 20 hasta finales de los 90 del siglo pasado. A través de archivos de productores, distribuidores, del recurso a las revistas de la época se prueban dos hipótesis: primera, en España el cine soviético que se pudo ver estuvo condicionado por los avatares de la historia (De un lado, en España la 2a República y la Guerra Civil (1931-1939), el franquismo, donde este cine estaba prohibido hasta que en 1966 se proyectó Don Quijote de Kozintsev, la llegada de la democracia y, de otro lado, la Unión Soviética, el estalinismo hasta 1953, el deshielo (1954-1961) y la Perestroika de Gorbachov. La segunda hipótesis es que el cine soviético fue conocido en círculos minoritarios y gracias al empeño particular de distribuidores o aficionados que por medio de cineo de ciclos en festivales difundieron este cine evitando así la censura.
\end{abstract}

Palabras clave: cine soviético, recepción de cine, Unión Soviética y España.

Este artículo de investigación científica y tecnológica hace parte de la investigación El mito del Quijote en la configuración de la nueva Europa, proyecto de investigación I+D, financiado por el Ministerio de Ciencia e Innovación de España (Dirección general de programas y transferencia de conocimiento. Subdirección General de Proyectos de Investigación).

Doctor en Historia del Arte (Ph. D. 1998) y Bachelor en Filosofía (B. A. 1996) por la Universidad de Navarra. Profesor Contratado Doctor (acreditado por ANECA) del Departamento de Cultura y Comunicación Audiovisual, en la Facultad de Comunicación de la Universidad de Navarra, España. Fulbright Visiting Scholar de estudios artísticos y gestión cultural en el Department of Fine Arts de New York University (NYU). Correo electrónico: jlatorre@unav.es.

"* Doctor en Comunicación por la Universidad de Navarra, Esapaña, y secretario del Departamento de Cultura y Comunicación Audiovisual. Correo electrónico: amartinez@unav.es.

... Doctor en Filosofía y profesor titular de la Facultad de Ciencias de la Información de la Universidad Complutense, Madrid, España. Imparte docencia en las áreas de Información Especializada, Información Cultural y Análisis cultural de la crítica cinematográfica. Correo electrónico: rafael.llano@ccinf.ucm.es.

\section{AGRADECIMIENTOS}

$\% \nLeftarrow$

Este artículo forma parte del proyecto El mito de 'El Quijote' en la configuracion de la nueva Europa, HUM2007-64546, financiado por el Ministerio de Ciencia e Innovación de España (Dirección General de Programas y Transferencia de Conocimiento. Subdirección General de Proyectos de Investigación). Un agradecimiento especial a Rafael de España, cuya lectura y consejos que han mejorado este trabajo. 


\title{
Acceptance of Soviet Cinema in Spain: a Story among Wars, Censures, and Apertures
}

\begin{abstract}
This article reconstructs the history of Soviet cinema exhibition in Spain since the 20 s to late 90 s of the last century. Through file producers and distributors, the use of magazines of the time tested two hypotheses. First, in Spain, the Soviet cinema that was shown was conditioned by the vicissitudes of history (one hand, in Spain the $2^{\text {nd }}$ Republic and the Civil War (1931-1939), the Franco regime, where the film was banned until 1966, when Kozintsev's Don Quixote was released in Madrid, the arrival of democracy and, on the other hand, the Soviet Union, Stalin until 1953, the Thaw (1954-1961) and Gorbachev's perestroika. And, second hipothesis, the Soviet cinema was known in circles minority and particular thanks to the efforts of dealers or amateur who, through films-club or films series at Film Festivals, broadcast these films avoiding censorship.
\end{abstract}

Key words: soviet cinema, films reception, Soviet Union and Spain. 


\section{Introducción}

El desarrollo del cine soviético ha estado condicionado por la historia política de España y de la Unión Soviética y por las dificultades comerciales en la distribución del cine no comercial. A través de archivos de productores, distribuidores, del recurso a las revistas de la época se pretende reconstruir la historia del cine soviético que se pudo conocer en España y de la influencia que tuvo sobre artistas y círculos culturales minoritarios. En una primera etapa, como ha estudiado Roman Gubern, el cine soviético se proyectó en torno a los intelectuales vinculados con la Residencia de Estudiantes y gracias al esfuerzo, entre otros, de Luis Buñuel. Tras la Guerra Civil y la instauración del franquismo, en 1939, las noticias sobre cine soviético que se tienen son gracias a corresponsales que desde el extranjero hablan de las películas a las que han tenido acceso, sobre todo en París. Hasta junio de 1966 estuvieron prohibidas en España las proyecciones de cualquier película producida en la Unión Soviético. En ese año, organizada por la Asociación de la Prensa, se permitió el estrenó de una película clásica, El Quiijote de Kozintsev, que había sido estrenada en festivales de cine europeos y en Moscú en 1957. Desde entonces, en festivales y en cineclubes se organizaron ciclos dedicados al cine soviético clásico y al nuevo cine soviético que se permitió exportar. La llegada de la democracia a España y la llegada de la política de Glasnot a la Unión Soviética permitieron conocer la obra de algunos directores más. Y en la actualidad, gran parte del cine ruso que se proyecta en España es en festivales de cine. La recepción del cine soviético en España, como se verá, es una historia que habla de las relaciones culturales entre Rusia y España que va más allá del cine y del siglo XX, como así lo muestran, además, algunas de estas películas.

Por ejemplo, en el documental de Alexander Sokurov, "Elegía de la vida. Rostropovich. Vishnevskaya" (2006), Mstislav Rostropovich muestra a Sokurov un organillo que guardaba en su casa de Moscú. "Es un regalo de la Reina de España, Sofía de Grecia" le dice, mientras hace salir del aparato una música de feria española. Esta melodía suena durante unos minutos a la vez que la cámara nos muestra el rostro sonriente de Rostropovich. El músico mueve la manivela con toda su energía de intérprete, disfrutando como si fuera un niño en esa simple operación que le permite evocar en su imaginación el lejano país mediterráneo. Esta historia, como se verá, es la historia de una relación cultural entre España y Rusia que va más allá del cine y más allá del siglo XX, como se muestra en algunas películas.

El filme de Sokurov se presentó en España en el Festival de cine documental Punto de Vista, celebrado en Pamplona en febrero de 2007, casi un año después de su estreno en el festival de Locarno (Suiza). Este caso ilustra no solamente la visión de ensueño sobre España presente en el imaginario ruso sino también la forma de distribución, minoritaria pero apasionada, que ha tenido el cine ruso en España. Aunque el festival navarro de cine documental Punto de Vista se está convirtiendo en un punto de encuentro del documental internacional, no deja de ser un raro acontecimiento de provincias, que nada tiene que ver con los circuitos comerciales por los que discurre el cine nacional.

Así ha ocurrido durante la segunda mitad del siglo XX. Sólo algunas compañías incluyeron en sus catálogos producciones rusas: Filmófono a comienzos de los años treinta y Alta Films desde finales de los setenta. La inexistencia entre estos dos momentos de iniciativas comerciales serias (más allá de la programación de festivales, sesiones de cineclub, retrospectivas sobre directores rusos, cursos de verano o seminarios) manifiesta muy bien el enorme vacío de intercambio cultural que se dio durante décadas entre ambos países. Se entiende así que la idea del alma común de Rusia y España, que tiene fuertes raíces literarias, no tenga un equivalente cinematográfico.

No es anecdótico, de hecho, que fuera un Don Quijote, en la adaptación de Kozintsev, la primera producción soviética que se estrenó en España durante el Franquismo. Ese Don Quijote servía ya entonces para explicar a los propios rusos los peores años del estalinismo, y permitió también a una generación de españoles saber que existía una tradición cinematográfica de enorme calidad 
en el otro extremo de Europa; un cine que valía la pena conocer y darlo a conocer a los propios compatriotas. Estamos ya en el año 1966, después de más de dos décadas de silencio total en España de todo lo relacionado con la Unión Soviética. El Quijote se había convertido en un puente que permitía superar todo tipo de fronteras y de censuras, uniendo estos lejanos países hermanados en su quijotismo.

Esta película tenía un sentido simbólico por la larga tradición de quijotismo que hay en la literatura y en la cultura rusa. Como ha estudiado Bagnó, el quijote es el mito extranjero que mayor influencia ha tenido en la cultura rusa (Bagno, 1994, p. 15); por encima de los avatares de la historia reciente, con itinerarios políticos opuestos, la huella común de El Quijote nos recuerda los puntos que unen a rusos y españoles y nos distancian de otos países centroeuropeos: una capacidad de soñar más allá del crudo realismo del presente que nos ha tocado vivir, una locura que lleva a luchar por causas más o menos utópicas y, también, aunque no nos guste reconocerlo, algunas consecuencias inquisitoriales por exceso de celo e idealismo. De hecho, a los héroes de la Revolución (y a los rusos en general) que supieron contagiar su idealismo socialista al mundo entero se les podía aplicar la misma descripción con la que el historiador Henry Thomas Buckle (que Dostoievski confesaba haber leído con suma atención, y constituyó también una fuente histórica de documentación sobre España para las generaciones posteriores) aplicaba al pueblo español:

Ningún otro país europeo dio al mundo tantos predicadores intrépidos y altruistas, tantos mártires valientes y abnegados, a personas que sacrificaban gozosamente su vida para difundir las verdades que consideraban necesarias... Sin embargo, la sinceridad y honradez de los propósitos que han distinguido siempre al pueblo español, considerados en conjunto, muy lejos de evitar las persecuciones religiosas las facilitaban más bien... el exceso de celo originaba, como es natural, la crueldad, preparando así el terreno para que la inquisición echara raíces y floreciese. Los promotores de esa bárbara institución no eran hipócritas, sino entusiastas. Buckle H. T., Historia de la civilización en Inglaterra (Bagno, 2006, pp. 245-

254).

Quizá estén también relacionados con esta alma común, un tanto extrema de Rusia y España, los avatares históricos que han impedido que el cine de ambos países se encuentre de modo tan universal y profundo como su literatura. Sea por lo que fuere, el hecho es que la llegada del cine ruso a España ha sido el viaje de un solitario caballero andante que tuvo que enfrentarse a los destrozos de dos guerras, a los molinos de las censuras de dos países y, más recientemente, a la difícil distribución de un cine artístico en el entorno de una cultura global que le exige transvertirse de entretenimiento.

\section{Metodología}

Este artículo se basa en los datos documentales que ofrecen libros de historiadores del cine (Gubern, Sánchez Noriega, Rimbau, Torreiro, Cabeza, Heredero y de España entre otros). También en las reseñas sobre estrenos de la Gaceta literaria, revista cultural de los años 20 y 30 del siglo pasado. También se han consultado los catálogos de las productoras que, con distintos nombres, contaban entre sus fondos con títulos rusos.

A partir de estos datos y de la labor de hemeroteca se ha reconstruido la historia de la difusión del cine soviético en las pantallas españolas.

En anexo se adjuntan dos cuadros. El primero de ellos reúne las películas citadas en La Gaceta Literaria o proyectadas en alguna sesión del Cineclub Español entre 1927 y 1931. El segundo, cuadro II, películas rusas que forman el catálogo de Altafilms a comienzos de los años 90 .

\section{Difíciles comienzos entre dos guerras civiles}

¿Cuándo comenzó esta precaria pero apasionada relación entre el cine soviético y el público español? En el Proyector de luna. La generación del 27 y el cine, Román Gubern ha documentado estos inicios tardíos. Entre las primeras películas soviéticas que 
se proyectaron en España se encuentra El acorazado Potemkin, (Bronenosets Potiemkin, 1925) de Serguéi Eisenstein, estrenada en noviembre de 1930 en Barcelona. Según Gubern, Luis Buñuel había asistido a la primera proyección de esta película en París, y el impacto que ejerció sobre el director fue tal que afirmó que era la película más bella de la historia del cine. Unos años después, en mayo de 1931, Buñuel como responsable del Cineclub Español hizo que se proyectara con ocasión de la proclamación de la II República.

La recepción de esta película en España no fue distinta de la que conoció en Alemania o en Francia: se vio como una obra maestra del arte cinematográfico y a la vez como un canto a seguir la revolución que había comenzado en Rusia. Luis Gómez Mesa, uno de los fundadores del Cineclub Español, recordaba así la primera proyección de la película en Madrid:

La película fue muy aplaudida -a veces ovacionada- tuvo los efectos temidos por las esferas oficiales, pese a lo que garantizaban los organizadores. Al salir el público, que llenaba el Palacio de la Prensa, en la propia Plaza del Callao, se formó una manifestación -no autorizada, claro es- vociferante, de gritos revolucionarios, que avanzó por la Gran Vía, con el consiguiente susto de los tranquilos transeúntes, y que se dispersó en la calle de Alcalá, frente al Ministerio de Instrucción Pública. Algunos grupos continuaron hasta la Plaza de Cibeles. ¿Consecuencias de lo sucedido? Incautación de la película y su prohibición definitiva.

No sería un caso aislado; Román Gubern documenta también cómo en 1933, una proyección de El acorazado Potemkin, organizada por el Sindicato de Trabajadores del Puerto en Sevilla en 1933 y a la que asistieron 5000 personas se prohibió para evitar disturbios públicos (Gubern, 1999, p. 377).

El hecho de que el primer cine ruso que llegó a España fuera el cine más politizado, explica que las producciones y los cineastas soviéticos fueran vistos como un peligro ya durante la República.
Asimismo, esto nos permite entender porqué este cine se difundió en España a través de vías minoritarias, en desigualdad de oportunidad con otros cines del momento. La filmografía soviética que los españoles conocieron se limita a películas hechas en los primeros años de estalinismo, cine de vanguardia tanto en lo estético como en lo político. La recepción más abierta -artística- que estaban teniendo otras películas de vanguardia como Un Chien Andolou (Un Perro andaluz) de Buñuel, quedó así comprometida con un ámbito político determinado de izquierdas, que no era ni mucho menos el exclusivo de los intelectuales españoles del momento, que hubieron de sufrir después persecución y muerte en ambos frentes de la Guerra civil española.

En gran medida, el primer cine soviético se proyectó gracias al interés de gentes del mundo del cine, afines a las ideas del Partido Comunista. Juan Piqueras es una de estas personalidades que influyeron en la distribución del cine soviético en España. Al igual que Buñuel, tuvo oportunidad de ver en París las películas realizadas entre 1925 y 1930, y que habían sido seleccionadas por el gobierno de la URSS para su exportación. Este conocimiento adquirido en Francia les permitía dar noticia de estas películas mediante artículos en revistas como La Gaceta Literaria y, más tarde, en Nuevo Cinema, que había sido fundada por el propio Piqueras. Desde París, estos pioneros hacían también lo posible para que las películas de los grandes maestros del cine soviético se programaran dentro de las sesiones del Cineclub Español.

Pero, junto a su utilización partidista, otro aspecto que merece la pena destacar para entender la dificultad de distribución del cine ruso en la España del momento es el de su clasificación como cine de vanguardia. El cine de vanguardia se oponía al comercial o de mero entretenimiento. El propio Piqueras, haciéndose eco de los incidentes del estreno de la primera película de Buñuel y Dalí en Madrid, escribe lo siguiente: "Ante todo, es necesario darse cuenta de que al Cineclub no puede -no debe- acudirse con la única y exclusiva disposición de divertirse, de entretenerse solamente. Las finalidades que el Cineclub persigue son muy otras. Es el deseo de una valoración actual y de 
una revisión lo que lo anima" (La Gaceta literaria, 15 de diciembre de 1929).

El Cineclub Español existió entre 1929 y 1931 , y fue creado en torno al grupo de personas que escribían de cine en La Gaceta Literaria y dirigido en sus últimas sesiones por Luis Buñuel que, entre mayo de 1927 y diciembre de 1928, había organizado en la Residencia de Estudiantes unas sesiones para conocer el último cine que se estaba haciendo en Europa. Si pensamos en los residentes que entonces convivían en esa institución mítica para la cultura española de los años 30 (el mismo Buñuel, Federico García Lorca, Salvador Dalí, Manuel de Falla o Pepín Bello), nos damos cuenta de la privilegiada influencia que pudo tener culturalmente este cine en la sociedad más liberal. Era un público que formaba la minoría intelectual en el sentido que Ortega y Gasset habla de ello en La revolución de las masas. Según Gubern, en la primera lista de socios, junto a nombres relevantes de la aristocracia, aparecen también los de José Bergamín, Rafael Alberti, Federico García Lorca, Ramón Gómez de la Serna, Vicente Alexandre, Rosa Chacel, Moreno Villa, Alberto Jiménez Fraud, Antonio Marichalar, Eduardo Ugarte, José López Rubio, Antonio Regoyos, Carlos Arniches, Luis Lacasa y Fercando Carcía Mercadal, Rodolfo Halfter, Tomás Navarra Tomás, Nicolás y Ricardo Urgoiti, Enrique Díez-Canedo, Maruja Mallo, Benajamín Plencia, Ricardo Baroja y José María Dorronsoro. Intelectuales, poetas, pintores, arquitectos, filólogos, músicos. Miembros todos del renacer cultural que en España se llamó como en Rusia, la Edad de Plata (Gubern, 1999, p. 370). De hecho, las películas eran vistas por la mayoría de estos intelectuales como experimentos de la renovación de las artes y como ejemplos de lo que el cine podía llegar a expresar. Para algunos, como Buñuel, sirvieron para ahondar en el surrealismo; para otros como César M. Arconada, serían ejemplos del arte futurista tan vinculado a la Revolución. Gubern habla incluso de la influencia de la fotografía y del cine soviéticos que se puede apreciar en la puesta en escena de las obras teatrales que estrenó Federico García Lorca por aquel entonces.

Tras la desaparición del Cineclub en 1931, estas películas se pudieron seguir viendo gracias a dos empresas quijotescas: la madrileña Filmófono, fundada por Ricardo Urgoiti, y la barcelonesa Cinaes, que era sobre todo una distribuidora. Las dos empresas importaban películas extranjeras, entre ellas las soviéticas, para su distribución en España; pero aunque estas productoras y distribuidoras tenían salas en las principales ciudades españolas, la exhibición de estos filmes no fue nunca masiva, por lo que su influencia resultó más decisiva en lo artístico que en lo político. Seguían proyectándose fundamentalmente películas de la etapa inicial del cine soviético, de los directores que podemos considerar los grandes maestros (Vertov, Eisentein, Pudovkin y Dovzhenko principalmente), pero nada del cine prerrevolucionario. Los espectadores de estas sesiones eran intelectuales y artistas que vivían un momento de renovación cultural, a imagen de lo que sucedía en toda Europa. Fuera de este ámbito más creativo, las producciones soviéticas tendrían una difusión mayor en los años del Frente Popular, en los estertores de la II República y en los primeros años de la Guerra Civil (1935 y 1936), con un fin ya claramente propagandístico. Entonces el cine soviético era difundido también en revistas militantes como Octubre o Nuevo Cinema y en revistas de partido como Hora de España, editada por el Frente Popular.

\section{Guerra civil (1936-1939)}

En general, este tipo de películas soviéticas clásicas tendrían su mejor momento de difusión durante los siguientes años de guerra (1936-1939) en la zona republicana, al amparo del Partido Comunista y con el sueño de extender la revolución en España. Fueron los comunistas de los sindicatos quienes se ganaron mayor prestigio en la exhibición cinematográfica de guerra, gracias a que sus consejos obreros dominaban en las salas. Pero todos estos esfuerzos por "saturar de moral" la retaguardia, mostrando el heroísmo de las trincheras para unir al pueblo en la resistencia, no dieron muchos frutos. La mayoría de las películas que se proyectaron perseguían el fin opuesto: huir del escenario bélico. Por eso sus efectos fueron más limitados de lo que se piensa, como ha estudiado José Cabeza (Cabeza, 2005). 
En el período de dominio de la UGT, uno de los principales sindicatos de obreros de España vinculado al Partido socialista, sólo se proyectaron once sesiones de películas soviéticas: La patria os llama, Camino de la vida (Nikolai Ekk, 1931), Los marinos de Kronstadt, Juventud triunfante, y El circo (que se proyectó seis veces, y era una comedia musical producida en el 36). En el mismo período (diciembre del 36 hasta marzo del 37) se proyectaron en las salas ugetistas 55 sesiones de películas estadounidenses, aunque seleccionando aquellas de ideología más liberal, o por lo menos no contraria a la revolución social, como por ejemplo Rebelión a bordo (Frank Lloyd, 1935), que fue la que más se proyectó, y que recordaba vagamente al tema de El Acorazado Potemkin. En general, la admiración por la URSS no se tradujo en una exhibición incondicional de sus películas. Se imponía la jerarquía de fines: primero estaba la supervivencia de la industria. El mensaje ideológico que podía transmitir una película de ficción era un argumento para tener en cuenta al decidir su proyección, pero nunca tan decisivo como para hacer peligrar las cuentas de una sala, también de UGT o CNT (sindicato anarquista). Según Cabeza,

... las exportaciones a España de películas soviéticas resultaron, pues, relativamente bajas. En 1934, la URSS representaba un escaso 0'4\% de cuota de importación de películas en España (dos en total) frente al 52'7\% de EE. UU. (250 películas), 21,1\% de Alemania (100 películas) o el 15,8\% de Francia (75 películas). Y también cuando llegó la guerra, el número de películas sociales que se importaron para llenar el ocio de muchos cines fue pequeño -un irrisorio 3,7\%-en comparación con el cine americano. De las 154 proyecciones semanales de películas soviéticas, un $30 \%$ se vio entre octubre de 1936 y enero de 1937, y un 43\% se proyectó durante 1937. El acorazado Potemkin no se vio en los circuitos comerciales, la Línea general apenas estuvo en cartelera cuatro semanas y Los marinos de Cronstadt apareció 11 veces y casi todas entre octubre de 1936 y enero de 1937. La película que más veces se repitió fue El circo, con 17 semanas en cartelera, y eso porque se parecía más a Hollywood en su forma, con villano, heroína perseguida y niño querido (Cabeza, 2005, pp. 217-218).

Como ha estudiado Sasha Markus, el cine del realismo socialista concebido en la URSS durante los años treinta, al igual que otros cines de estilo clásico, tenía sus géneros y Star system. Los héroes (obreros o campesinos que adquirían conciencia social y luchaban por la Revolución, o en tiempos de paz, por el mantenimiento del sistema) pasaban todo tipo de avatares, pero triunfaban en sus ideales, con un final siempre feliz (Markus, 2006, pp. 13 y ss.). Una de las películas paradigmáticas que pudo verse en Barcelona en el período anterior a la Guerra Civil fue Tchapaief (Chapaev, el guerrillero rojo, 1934), de Georgi y Segei Vasilyev (Kharitonova, 2005), que despertó interés en la prensa. Otro ejemplo de este género es Odna (Sola, Grigori Kozintsev y Leonid Trauberg, 1931), que trata de una maestra que va a trabajar al monte Altai, en Asia Central, y tiene que luchar en solitario contra el ambiente "retrógado", es decir, ignorante, supersticioso y machista de la zona más rural, aún no transformada por la revolución (Heredero, 2008, pp. 308 y ss).

De todo esto se deduce que el público que frecuentaba esta escuela cinematográfica era muy escaso. E, incluso, durante la guerra, quedaba claro que proyectar un tipo de cine a contracorriente del gusto del público y de forma masiva provocaba el colapso de la red de salas por la ausencia de espectadores. El cine soviético se veía como un mundo parcial y extraño; representaba el ideal del público que se quería tener, pero no el del público real, mientras que la industria americana ya había desarrollado unos personajes y modelos que se adecuaban al público que pagaba la entrada. Consciente de este problema, en 1938, Felipe Pretil, secretario general de la FEIEP, defendía públicamente la nacionalización de la industria del espectáculo para que el Gobierno de la República hiciera de los locales de divertimento una "palanca más para nuestro anhelo común: ganar la guerra". Se proponía la creación de una escuela de dirigentes de espectáculos y premiar al más capacitado de esta nueva elite con un viaje a la URSS. Allí podría terminar su formación "visitando las organizaciones similares a las que 
integran esta federación en la URSS". Se buscaba, en definitiva, la orientación artística y los modelos del cine soviético. Como resume Cabeza, "si Rusia nos sirve de guía, ejemplo y enseñanza, volvamos los ojos a Rusia y a su revolución de 1917 para encontrar en ellas los argumentos en que basamos nuestra proposición" (Cabeza, 2005, p. 172). Pero ya era demasiado tarde, pues la Guerra Civil se decantaba por el bando contrario.

\section{Un Quijote soviético para la España de Franco}

Durante la dictadura de Franco, el cine soviético corrió la suerte de todo aquello que, aunque fuera de lejos, recordara al bando republicano: pesaba sobre él una prohibición estricta. Así transcurrieron las tres primeras décadas de la dictadura, que sólo conocieron una excepción: la autorización para importar el Don Quijote de Kozintsev (Leninfilm, 1957). El productor y distribuidor español, Cesáreo González, presidente de la famosa Suevia Films, era amigo personal de Franco y colaborador suyo no sólo en lo relativo a la importación y exportación del cine español que Cesáreo produjo esos años con notable éxito, sino también en la promoción de espectáculos españoles en el extranjero. Fue este empresario gallego, por ejemplo, quien, después de haber producido siete u ocho largometrajes sobre la cantante folclórica Lola Flores, en los años cincuenta, organizó una gala de la actriz en Moscú. El presidente de Suevia Films había ya tratado de obtener autorización para importar el filme de Kalatozov, Cuando pasan las cigüeñas (Letjat zuravli, Mosfilm, 1957); pero ni el galardón que la película obtuvo en el Festival de Cannes ese año, ni los elogios de la crítica internacional lograron vencer los prejuicios que en el régimen existían contra todo lo soviético. Lo único que parecía justificar su exhibición era el hecho de que se tratara de una adaptación del Quijote, el valor cultural más importante del país, y que más veces ha sido llevado a la pantalla como ha estudiado recientemente Rafael de España (España, 2007). Por tanto, la primera película soviética que se estrenó después de la guerra, ya en junio de 1966, en los cines Palafox de Madrid y en versión doblada al castellano, fue la de Kozintsev. Sánchez Noriega estudia la recepción de esta película en la prensa del momento y, de acuerdo con él, "se juzgó como la mejor adapación de Cervantes hasta la fecha" (Sánchez Noriega, 2005, p. 96).

Existían también otras razones que explican el estreno de esta película en España. En diciembre de 1965, coincidiendo con el cambio aperturista del Ministerio de Cultura (Manuel Fraga había sustituido a Arias Salgado), se había dictado una ley que autoriza la importación de películas de la URSS, aunque con una serie de cortapisas que no quedan explicitadas pero se daban por supuestas, y se pueden resumir en la ausencia total de contenidos ideológicos. Cesáreo González aspiraba a poder vender en la URSS sus productos nacionales, y por eso fue uno de los primeros en secundar la invitación del Ministerio a normalizar relaciones. Por otro lado, tras el primer deshielo, los soviéticos estaban promoviendo un cine menos politizado que el anterior, con atención a productos espectaculares ambientados en el pasado. No es de extrañar que, tras el Quijote, Cesáreo trajera a España películas como la tetralogía de "Guerra y paz" (la primera parte, "Austerlitz", se estrena en diciembre de 1967), el "Hamlet" de Kozintsev, "La borrasca" ("Metel", 1964, estrenada en 1968), "El planeta de las tormentas" ("Planeta bur", 1962, estrenada en 1969) y "Tchaikovski" (1969). También otras distribuidoras presentaron películas de similar estilo histórico y comercial: Discentro distribuyó "Nastenka" ("Krepostnaya aktrisa", 1963) en 1968; Incine trajo "Ana Karenina" (1967) en 1970. Y la propia Alta Films, que será protagonista del cambio posterior, ya a finales de los 70, distribuyó algunas cintas musicales como "El lago de los cisnes" ("Lebedinoe ozero", 1968; estrenada en 1973) o "Poema de la danza (Carmen)" ("Poema o tantse", 1969; estrenada en 1974).

Don Quijote de Kozintsev fue como una punta de lanza del cine soviético en España. En una rueda de prensa que dio en Cannes el mismo año del estreno, el director declaró que había respetado al máximo el libro de Cervantes y que sólo se había permitido las modificaciones mínimas que exigía la adaptación de una novela tan extensa al metraje y características propias del lenguaje fílmico. No es 
así, obviamente: el Quijote de Kozintsev, sin dejar de ser universal, habla para su tiempo y desde su tiempo, y es marxista y sutilmente politizado (Cfr. Arran, 2005, p. 76). Tiene frecuentes guiños políticos que afectaban a la España del momento: "Tú y yo estamos solos en España", le dice don Quijote al león, aludiendo implícitamente a la falta de idealismo tras el fracaso de la República. Del mismo modo, el que la visión de Kozintsev sigue siendo soviética de fondo lo muestra el especial ensañamiento con las clases más pudientes, y la exaltación de personajes como Sancho, que adquiere mayor protagonismo que el mismo don Quijote. "Yo puedo hacer cualquier cosa -le dice éste al cortesano que lo expulsa de Barataria- ¿y tú, parásito?". Sancho no es el personaje antagónico y a la vez complementario del Quijote que creó Cervantes, sino otro idealista, pero con más sentido común que su señor. Por eso sabe ganarse a las gentes sencillas (a cuya clase social pertenece), aunque las autoridades le impidan finalmente gobernar prudentemente. Consecuente con la herencia ilustrada del marxismo, Kozintsev sitúa también a la Iglesia y la nobleza en el mismo plano que les corresponde como "opio del pueblo". Igual que el fraile dominico, los duques de Kozintsev se aprovechan de la inocencia del caballero con una crueldad que no deja lugar alguno para el humor, a diferencia de lo que ocurre en la novela de Cervantes, que pone lo siguiente en boca de su pseudoautor: "Y dice más Cide Hamete; que tiene para sí ser tan locos los burladores como los burlados, y que no estaban los duques dos dedos de parecer tontos, pues tanto ahínco ponían en burlarse de los dos".

Altisidora, por último, no es simplemente una doncella descarada, sino que es la gran antagonista de la campesina Aldonza, la perdición del hidalgo, al arrastrarlo a la corte y alejarlo del pueblo, mientras exclama: "Por semejante bufón el duque me estará eternamente agradecido". Su crueldad de mujer fatal llega al extremo tras la falsa resurrección, momento crucial en el que se produce una de las distancias más marcadas de la película con la novela (en la que se omite semejante desenmascaramiento cruel de la broma), con la intervención expresa del duque: "No os ofendáis, señor don Quijote. Es una broma, una comedia, como todo en este mundo. Sois precisamente un maestro en este oficio. Nos habéis demostrado de forma altamente convincente que la conducta virtuosa es ridícula, la fidelidad es grotesca y el amor una invención de la imaginación calenturienta".

Junto con la villanía y depravación de Altisidora, estas notas de realismo cínico hacen que la versión de Kozintsev haya sido considerada como un don Quijote desesperanzado. Pero sabemos que su final abierto -cuando todo parece hundirse, el caballero es redimido por la amistad del pueblo sencillo, representado por Sancho y Aldonza- deja lugar a la utopía. Y esta visión romántica del Quijote, presente todavía en el mundo soviético, era también la que manifiesta la versión cinematográfica más popular en la España del momento, la de Rafael Gil, producida por CIFESA en 1948, y que termina de modo similar: con Don Quijote, ya muerto, volviendo a los campos de la Mancha con su fiel escudero mientras un letrero en sobreimpresión nos informa de que "aquello no fue el fin, sino el principio". Es curioso que coincidan en un final similar dos versiones ideológicamente tan distintas; como también similar es la evocación del paisaje manchego que hacen ambas, aunque en este último caso se trate de Crimea. Recordemos que el director artístico del Don Quijote de Kozintsev, Nathan Altman, contaba con el asesoramiento del artista español, y manchego para más señas, Alberto Sánchez, que estaba exiliado en Moscú desde el final de la Guerra civil española. Paradojas del destino, si la película de Kozintsev recrea la Mancha castellana en Crimea, la famosa versión americana de Doctor Zivago (David Lean, 1965), se rodó en su mayor parte en España con escenarios igualmente verosímiles, recreando los primeros años de la Revolución rusa.

\section{Otros "quijotes" del cine soviético en España}

A mediados de los años sesenta entran en escena Juan Manuel López Iglesias y Yelena Samarina. Juan Manuel era hijo de españoles, evacuado durante la contienda civil a la URSS. Allí se había criado 
y educado, y casado finalmente con una actriz rusa, Yelena. Ambos habían abandonado Moscú para instalarse en Madrid. Yelena participó en varias películas, algunas de ellas producidas por el mismo Cesáreo González. Juan Manuel López creó en 1969 una empresa de distribución de cine, Alta Films. Su objetivo principal era facilitar, gracias al conocimiento del idioma ruso y de los mecanismos de la administración soviética que ambos tenían, la relación entre los distribuidores y exhibidores españoles, por una parte, y Sovexport - el departamento de Mosfilm encargado de las exportaciones - , por otra. Ya hemos visto que gracias a Alta Films se estrenaron en España, en 1967 y 1968, algunos episodios de la adaptación cinematográfica de la novela Guerra y Paz, de la que fue responsable Serguei Bondarchuk. Y, más adelante, también pudo verse Derzu Uzala, dirigida en 1975 por Akira Kurosawa para Mosfilm, y que obtuvo el Oscar a la mejor película extranjera ese año.

Pero para que Alta Films llegara a ser la verdadera protagonista de la presencia del cine soviético en España, tuvieron que pasar dos cosas. Primero, que se muriera Franco, pues, hasta su muerte en 1975, el régimen no cedió un ápice en sus principios de exclusión de lo soviético, con las excepciones comentadas. Y segundo, que la empresa de distribución cambiara de dueño, cuando a partir de 1973, tras el fallecimiento de Juan Manuel, Yelena Samarina se vio desbordada por la gestión de la empresa y decidió traspasarla a Enrique González Macho.

González Macho no se hizo cargo de Alta Films en España hasta 1984 (Riambau y Torreiro 2008, p. 386), después de varios viajes a la URSS, había comprado los derechos de exhibición por veinte años de los clásicos soviéticos y del cine del deshielo. Gracias a esta compra tardía, las películas de Eisenstein, Pudovkin, Dovdzhenko, Barnet, Kozintsev, Romm..., podían verse al fin de modo natural en las pantallas de los cines de arte y ensayo de Madrid -el California, el Bellas Artes, etc.-, y ser distribuidas por toda España, en las salas de cine-clubes. Esto supuso un cambio radical con respecto a los tiempos anteriores, pero no la difusión masiva esperada. Esta difusión corría ya a cargo de las distribuidoras americanas.

Junto con Alta Films, el otro evento protagonista de la presencia del cine soviético en España fue la Semana Internacional de Cine de Autor de Benalmádena. Este festival de cine, puesto en marcha en 1969 por el ayuntamiento de esta localidad malagueña, fue la única puerta abierta a un cine más comprometido socialmente que el que se estrenaba habitualmente en España, durante los últimos años del franquismo; con una orientación ideológica netamente de izquierdas en ocasiones (de hecho, Julio Diamante, que fue el director del festival desde 1971 hasta su conclusión en 1980, era un reconocido comunista).

En las tres primeras ediciones de la Semana de Benalmádena pudieron verse algunos títulos recientes de cine yugoslavo, húngaro y checoslovaco, junto con las producciones alemanas y francesas -muy pocas americanas-, que repartieron su presencia en las distintas secciones del festival. El primer largometraje soviético que se proyectó fue Andréi Rublev (1966-1967) de Tarkovski, en la edición de 1972. En ese año, que se suprimió el carácter competitivo del festival, Julio Diamante quiso hacer un homenaje a Anatole Dauman, el presidente de Argos Films (París), que estuvo presente en Málaga. Es muy posible que la copia de Rublev exhibida en Benalmádena procediera precisamente de esa distribuidora francesa, que ya por entonces tenía los derechos de exhibición del filme de Tarkovski en Francia. La película, en efecto, había salido de su extraño cautiverio de tres años, con su estreno internacional, fuera de concurso, en el Festival de Cannes de 1969 —donde obtuvo el FIPRESCI_- y aunque las dificultades para una distribución ordinaria del filme se habían renovado desde esa fecha, los estrenos comerciales de Andrei Rublev se sucederían en Europa sin interrupción desde 1972.

La proyección ese año de Andréi Rublev en Benalmádena acercaba a la crítica española a uno de los "mitos" de finales de los años sesenta y comienzos de los setenta en toda Europa. Pero además, en un país donde no se concebía el estreno de ninguna producción soviética, la llegada de Tarkovski se anunciaba como una pequeña, 
pero esperanzadora, ventana abierta al mundo. En concreto, esta película de Tarkovski debió gustar mucho, porque al año siguiente, 1973, volvió a proyectarse en Benalmádena un nuevo título del director ruso: Solaris (1971). Además, esta nueva edición dedicó un ciclo-homenaje a otras grandes producciones del cine soviético. Con el título "Ciclo Kozintsev y Trauberg: la fábrica del actor excéntrico", la V Semana Internacional de Cine de autor de Benalmádena mostró por primera vez en España El abrigo ("Shiniel", 1926), de G. Kozintsev y L. Trauberg; La nueva Babilonia ("Novi Vavilon", 1929), también de Kozintsev y Trauberg; La juventud de Máximo ("Yunost Maksima", 1934), de los mismos directores; Las extraordinarias aventuras de Mr. West en el país de los Bolcheviques (1924), de Lev Kulechov, 1924; El sastre de Torjok ("Zakroishik iz Torzhka", 1925), de Yakov Protozanov; El proceso de los tres millones ("Protsess o trioj millionaj", 1926), de Yakov Protozanov; La muchacha de la caja de cartón ("Dievushka s korobkoi"), de Boris Barnet; El rey Lear (1970), de G. Kosintzev, y La felicidad (1934), de Alexander Medvedkin.

Animado por el éxito del ciclo, Julio Diamante volvió a programar, para la VI Semana de Benalmádena (1974), un nuevo ciclo de cine ruso, consagrado esta vez a los maestros de los años treinta: Las ruinas del imperio ("Oblomok Imperii"), de Friedrich Emler; Suburbios ("Okraina", 1933), de Borís Barnet; Chapaiev, el guerrillero rojo (1934), de Serguei y Guerogi Vasiliev; La noche de San Petersburgo ("Peterburgskaia", 1934), de Grigori Rosal y Vera Stroieva; El circo ("Tsirk", 1936), de Grigori Alexandrov (que ya había sido proyectado en las sesiones del Cineclub Español, a finales de los años veinte, y durante la República); el musical Volga, Volga (1938), de Grigori Alexandrov; Los trece ("Trinadsat", 1936), de Mikhail Romm; La última noche ("Posliedñaya"), de Yuri Raizman; Una vela en el horizonte ("Belietet parus odinoki", 1937), de Vladimir Legoshim; Pedro el Grande ("Piotr Piervi", 1937), de Vladimir Petrov; La infancia de Gorki ("Dietstvo Gorkogo", 1938), de Mark Donskoi; Miembro del gobierno ("Chlien Pravitielstva"), de Alexander Zarji y Iossif Jeifits; y Una historia musical ("Muzikalnaia Istoria"), de Alexander Ivanovski y Herbert Rappaport. Por lo que se refiere a estrenos de producciones recientes, ese año se proyectó también en Benalmádena Pirostami (1969), de Giorgi Schengelaya.

El turno de Eisenstein y Dziga Vertov llegó en la VIII Semana de Cine de Autor, en 1976. Del primero se proyectaron en Benalmádena La Huelga ("Stachaka", 1924), Octubre ("Oktiabr"), Lo viejo y lo nuevo ("Staroie y Novoie", 1929) y El prado de Bezhin ("Biezhin lug", 1935), todas ellas estrenadas a finales de los años veinte en las sesiones del Cineclub de Buñuel. Y del documentalista soviético, el imprescindible Cine ojo ("Kinoglaz", 1924). En competición, se presentaron asimismo ese año dos películas soviéticas: El Sauquillo rojo, de Vassili Shuskin; y Feroz ("Liuti"), de Tolomush Okeyev. Todavía estuvo presente el cine soviético en las siguientes dos Semanas de Cine de Autor. En 1977, dentro del ciclo llamado "Operación apertura", se programaron tres películas que habían sido prohibidas por la censura para la edición de 1974: La fiesta de San Ioirguen ("Prazdnik sviatogo Iorguena", 1930), de Yakov Protazanov; y dos largometrajes de Kozintsev y Trauberg: El regreso de Máximo ("Vozvarschenie Maksima", 1937), y la Barriada de Vuiborg (1938). Finalmente, en la X Semana Internacional de Benalmádena, Yuli Riazman presentó Una mujer rara ("Stranaia Tchenshina"), y Larissa Sheptiko, dos largometrajes: Ty $i$ ya, y La ascensión ("Voskhozhdenie").

Para entonces, la transición política ya había comenzado en España. Y desde ese momento y hasta mediados de los años noventa, que concluyeron sus derechos de distribución, el Alta Films de Yelena Samarina primero, y luego de González Macho fue la distribuidora protagonista del cine soviético en España. Para hacerse una idea, el re-estreno de El acorazado Potemkin en los cines en 1977 y 1988, según los datos de Alta Films, convocó 227.2111 espectadores.

\section{Llegada del cine soviético desconocido}

En 1986, tras el congreso de la Unión de Cineastas Soviéticos, las autoridades soviéticas permitieron la exportación de películas desconocidas fuera de la URRS. El cine realizado clandestinamente 
en Mosfilm o Lenfilm que dormía en las filmotecas durante décadas comenzó entonces a ser conocido en Europa. En el festival de Cannes de 1987 se estrenaron algunas películas realizadas muchos años antes. Y hubo que esperar un año más para poderlas ver en España. Si, como venía siendo cada vez más habitual desde finales de los años treinta, era difícil hacer cine libre en la Unión Soviética, más difícil todavía era verlo en España.

En 1988 se organizó en Oviedo un ciclo de 62 películas soviéticas, la mayor muestra de cine de la URSS exhibida en España. El ciclo abarcaba desde el cine soviético clásico -Eisenstein, Vertov, Pudovkin- hasta los más significativos cineastas de la ola desencadenada por el cambio en la era Gorbachov, entre las que había películas de cineastas de la vanguardia en este movimiento liberalizador, como Klimov, Tarkovski, Guerman, Mijalkov, etc. Al margen de los "blockbuster" rusos distribuidos en España por las vías comerciales normales, el cine ruso y soviético se seguía exhibiendo en festivales y ciclos organizados por instituciones sin ánimo de lucro. En los últimos veinte años varios festivales han supuesto un hito en esta historia y han permitido el estreno de algunas películas soviéticas no vistas todavía en España. Ejemplos de estas proyecciones son el Ciclo Andrei Tarkovsky organizado en 1988 por el Cine Club Universitario de Belagua, que dirigía por entonces Rafael Llano en la Universidad de Navarra. Permitió ver la obra completa de Tarkovsky por primera vez y contó con la presencia de la viuda y el hijo del director ruso (Larissa y Andréi Andreevich) en Pamplona. En esta misma ciudad, con ocasión del Festival de cine documental de Navarra, se proyectó en 1999 la obra de Sokurov que hasta entonces no se conocía en España. Era un cine que mostraba ya sin tapujos algo que intuía la generación de la Edad de Plata y que Tarkovsky entendió como nadie: que el cine no era un arte fruto de la suma de otros artes, sino un arte nuevo. Y eso es quizá lo que le ha convertido en el mito de los más entusiastas cinéfilos, y en director de directores.

En el 2004, la Filmoteca Española organizó el ciclo "Hielos y deshielos: Otra historia del cine soviético (1926-1968)". Este ciclo pretendió hacer justicia a los directores que las dos censuras nos habían evitado conocer. Se estrenaron películas de Gerstein, Fiodorov, también musicales y comedias desconocidas. Películas que mostraban el otro cine soviético, el de entretenimiento. Pero también mucho del cine documental hecho en la Unión Soviética, no sólo en Rusia, se desconocía en España. En el 2005 se organizó en La casa encendida de Madrid "Ver sin Vertov", una muestra comisariaza por Carlos Mugiro que supuso la mayor retrospectiva de cine de no-ficción hecha en España (Mugiro, 2005). La muestra abarcaba desde 1954 hasta el 2004, y cubría producciones realizadas en muchas de las ex repúblicas soviéticas. Más de cincuenta documentales de directores como Herz Frank, V. Goulin, P. Kogan, N. Boromin, M. Romm, U. Brauns, S. Paradzhanov, A. Pelechian, Y. Podnieks, A. Sokurov, N. Mikhalkov, M. Goldovskaia, V. Semenjuk, V. Kossakovsky, Ni. Obukhóvich, A. Zagdansky, V. Kobrin, I. Seleckis, D. Zhelkovsky, S. Loznitsa, M. Dvorstsevoi.

Entre los festivales recientes donde se han proyectado películas rusas y soviéticas destacan: El Festival de cine de San Sebastián; el Festival Posible de Barcelona, dedicado al cine de Europa Central y Oriental; y el Festival internacional de cine de Gijón, que en su última edición hizo una retrospectiva titulada Vientos del Este. En este último, pudieron verse de nuevo los títulos más emblemáticos del cine hecho en la época del deshielo, de Tarkovski y Makavejev, entre otros. Este Festival se organizó conjuntamente con la Filmoteca de Valencia y el Centro Galego das Artes da Imaxe (CGAI), donde también se proyectaron las películas. Fruto de estos festivales es el libro Vientos del Este, editado por Carlos Losilla y J. E. Monterde, que recoge en su introducción el leitmotiv de la difícil distribución del cine ruso: "Un cine bastante mal conocido en España, -escriben los editores- ya que sólo una ínfima parte de estas películas fueron distribuidas en nuestro país -y muchas de ellas bajo el minoritario amparo del "arte y ensayo", aunque la esforzada labor del cineclubismo palió en buena parte ese desconocimiento" (Losilla y Monterde, 2006, p. 11). También la IV edición del Festival Internacional de cine documental de Navarra, Punto de Vista, que tuvo lugar en 2008, además de la Sección Oficial, se programó la retrospectiva "La 
forma que piensa. Clásicos contemporáneos del cine-ensayo" y el ciclo "Querido Andrei". Este ciclo consistió en el estrenó de películas que tienen a Andrei Tarkovski como tema, destino e inspiración.

La proyección del Don Kihot de Kozintsev, además de retomar las proyecciones de cine ruso en España interrumpidas durante décadas como vimos, coincidió con el regreso de muchos "niños de la guerra". Una generación que de manera quijotesca mantuvo vivos los vínculos entre las culturas rusa y española, con traducciones, montajes teatrales o mediante la labor de la distribución y doblaje del cine soviético. La generación de los hijos de aquellos "niños de la guerra" toma ahora el relevo. El moscovita Algis Arlaukas Pinedo, hijo de española y lituano, es un buen ejemplo de esta generación. Licenciado en el VGIK en 1987, se instaló en Bilbao hace 15 años, y ha estado haciendo cine y televisión en España desde entonces. Se trata de otras vías y otros frutos de la llegada del cine "soviético" a España.

\section{Conclusiones}

El cine ruso llegaba a España desde los años 20 del siglo pasado en cuentagotas, pero lo hacía de una forma entusiasta entre una minoría de cinéfilos que han mantenido a contracorriente en la sociedad el interés por uno de los cines más brillantes de la historia del séptimo arte.

En los años previos a la II República fue gracias al grupo de intelectuales reunidos en torno a las sesiones del Cineclub español que tuvo como responsable a Luis Buñuel. Durante la segunda mitad del siglo XX, sólo algunas compañías incluyeron en sus catálogos producciones rusas: Filmófono a comienzos de los años treinta y Alta Films desde finales de los setenta. La inexistencia entre estos dos momentos de iniciativas comerciales serias (más allá de la programación de festivales, sesiones de cineclub, retrospectivas sobre directores rusos, cursos de verano o seminarios) manifiesta muy bien el enorme vacío de intercambio cultural que se dio durante décadas entre ambos países. Se entiende así que la idea del alma común de Rusia y España, que tiene fuertes raíces literarias, no tenga un equivalente cinematográfico.
Durante varias décadas el cine ruso visto en España había sufrido tanto los mecanismos censoriales del franquismo como los de las burocracias de la URSS. Existieron vías por las que se pudo saltar sobre estos mecanismos, pero hasta la muerte de Franco y la llegada de Gorbachov no cambió esta situación. Sólo entonces se pudo ver en España un cine del que se había oído hablar o se conocía indirectamente por festivales extranjeros.

A pesar de todo, también en estos años de aislamiento motivados tanto por el franquismo como por el telón de acero, la cultura española no dejó de mirar hacia Rusia; y tampoco en la Unión Soviética se extinguió la influencia hispana. Los intentos de los gobernantes de romper esta relación tuvieron sus efectos, pero no pudieron eliminar lo más profundo de estos lazos comunes. Los itinerarios políticos opuestos seguidos a lo largo del siglo XX determinaron que ambos países sólo se hayan encontrado en algunas encrucijadas muy puntuales, que, como en la centuria anterior, se han construido sobre la base de influencias literarias, aunque fuera a través del cine. Este es caso de la tardía recepción fílmica de los grandes clásicos rusos a España o de la influencia de la literatura española del Siglo de Oro en Rusia, fundamentalmente el Quijote.

\section{Referencias bibliográficas}

Arran, D. F. (2005). Los quijotes de celuloide y el modelo original, pasando de puntillas por Orson Welles. En: Payán, M. J. (Coord.), El Quijote en el cine. Madrid: Ediciones Jaguar.

Bagno, V. (1994). El quijote vivido por los rusos. Madrid: CSIC.

Bagno, V (2006). El Gran inquisidor de Dostoievski: sus orígenes. En Bardenas, P. y del Pino, F. (Eds.). Frontera y comunicación cultural entre España y Rusia, Vervuert: Iberoamericana.

Cabeza, J. (2005). El descanso del guerrero: el cine como entretenimiento en el Madrid de la Guerra civil española (1936-1939). Madrid: Rialp.

De España, R. (2007). De la Mancha a la pantalla: aventuras cinematográficas del Ingenioso Hidalgo. Barcelona: Publicacions i Edicions, Universitat de Barcelona. 
Gubern, R. (1999). Proyector de luna. La generación del 27 y el cine. Barcelona: Anagrama.

Heredero, C. F. (1988). Cine soviético (1928-1962). Del ocaso de las vanguardias al eclipse de la primavera. En: W.AA. El cine soviético de todos los tiempos (1924-1986). Valencia: Filmoteca de la Generalitat valenciana.

Kharitonova, N. (2005). El cinema rus en la premsa catalana dels anys 30. Cineasta, n. 1, 2005. Recuperado el 10 de noviembre de 2009 disponible en www.casadelest.org/cineasta.

Markus, S. (2006). Por qué en el Este fue distinto: rasgos comunes, hechos diferenciales. En Losilla, C. y Monterde J. E. (Eds.). Vientos del Este. Los nuevos cines en los países socialistas europeos 1955-195, Valencia: Institut Valenciá de Cinematografia.

Mugiro, C. (2005), Ver sin vertov. Una introducción a cincuenta años de cine de no-ficción ruso y soviético (1954-2004). Madrid: La casa encendida.

Riambau, E. y Torreiro, C. (2008). Productores en el cine español: estado, dependencias y mercado, Madrid: Cátedra, Madrid, 2008

Sánchez Noriega, J. L. (2005) El idealista caballero andante en Crimea. Notas sobre la estética recepción del Quijote de KOZINTSEV, Grigori en Brihuega, J. y Sánchez, A. (Eds.). Memoria rusa de España, Alberto y El Quijote de Kózintsev. Madrid: Sociedad Estatal de Publicaciones, pp. 85-102. 